\title{
Akinetic Mutism and Cognitive-Affective Syndrome Caused by Unilateral PICA Infarction
}

\author{
YoungSoon Yang, M.D., Jung Eun Kim, M.D. , Jung Seok Lee, M.D. , SangYun Kim, M.D. \\ Department of Neurology, Seoul National University College of Medicine, Seoul, \\ and Seoul National University Bundang Hospital, Gyeonggi-do, Korea \\ ${ }^{a}$ Department of neurology, Konyang University Hospital, Daejeon, Korea \\ ${ }^{\mathrm{b}}$ Department of neurology, Cheju National University College of Medicine, Jeju, Korea
}

\begin{abstract}
A 42-year-old man with left posterior inferior cerebellar artery (PICA) infarction presented with akinetic mutism and cognitive impairment. Initially he suffered from akinetic mutism and MRI-documented infarction in the distribution of the left PICA. Twelve days later he developed cognitive impairment. Neuropsychological tests were performed, with the results corrected for age and education being compared with published Korean norms. Impaired performances were evident on executive function testing, with difficulties in planning, abstract reasoning, set-shifting, and perseveration. Akinetic mutism and cognitive-affective syndrome may be a manifestation of unilateral PICA infarction.
\end{abstract}

J Clin Neurol 3(4):192-196, 2007

Key Words : Akinetic mutism, PICA, Cognitive-affective syndrome

Akinetic mutism (AM) is characterized by sparse volitional motor and speech activation with moderately preserved arousal and vigilance functions. ${ }^{1,2}$ Spontaneous visual tracking of environmental stimuli is often intact. $^{3}$ The condition should be differentiated from other low-response states of similar clinical appearance such as the locked-in syndrome in which the motor pathways in the ventral pons are often injured. AM, the most severe of these disorders, is most commonly associated with bilateral hemispheric pathology, ${ }^{4}$ although unilateral lesions can also produce this condition. ${ }^{5}$ In adults a cerebellar cognitive affective syndrome has been described with a range of cerebellar pathologies. ${ }^{6,7}$ It is characterized inter alia by impairment of executive functions such as planning, verbal fluency, working memory, and personality change with blunting of affect or inappropriate behavior. It is usually associated with lesions involving the posterior lobe of the cerebellum and vermis. We describe a male patient with AM and cognitive impairment due to an ischemic stroke in the distribution of the left posterior inferior cerebellar artery (PICA). This report offers further insight into the mechanism of AM and cognitive impairment following unilateral cerebellar injury.

\section{CASE REPORT}

Our patient was a 42-year-old right-handed man

Received : September 4, 2007 / Accepted : October 24, 2007 / Address for correspondence : SangYun Kim M.D., Ph.D.

Department of Neurology, College of Medicine, Seoul National University, Seoul National University Bundang Hospital, 300 Gumi-dong, Bundang-gu, Seongnam-si, Gyeonggi-do, 463-707, Korea

Tel: +82-31-787-7462, Fax: +82-31-719-6815, E-mail: neuroksy@snu.ac.kr

* This study was supported by a grant of the Korean Health 21 R\&D Project, Ministry of Health and Welfare, Republic of Korea (no. A050079). 
(A)

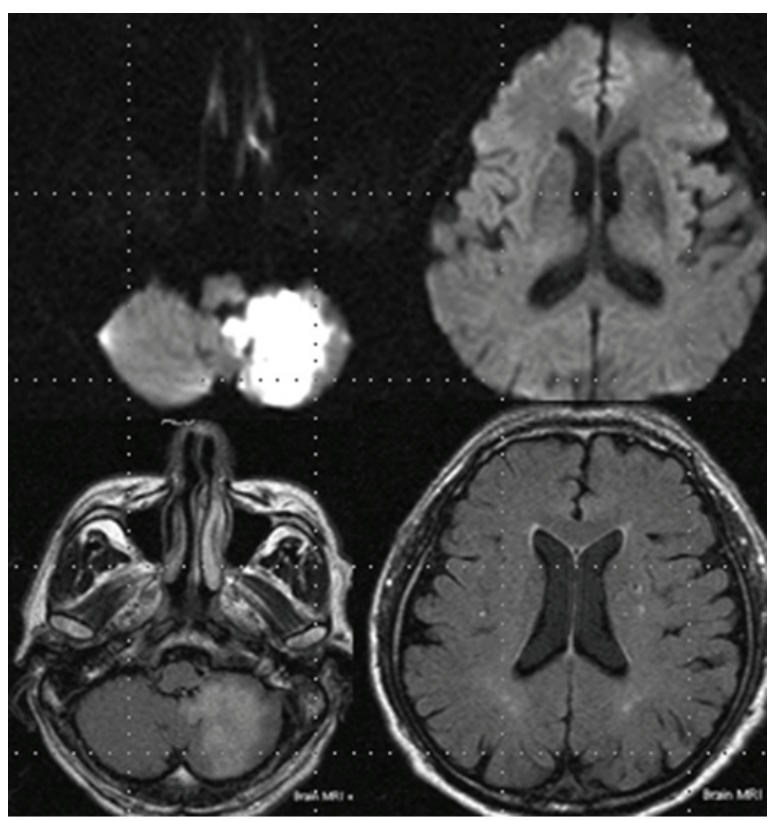

(B)

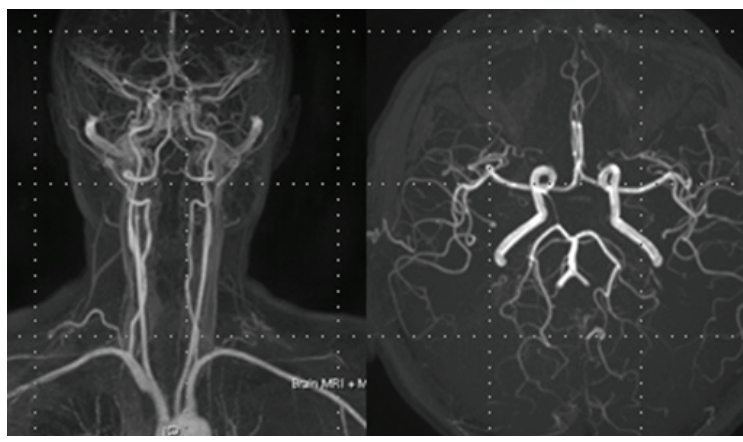

Figure 1. (A) Diffusion-weighted magnetic resonance imaging and fluid attenuated inversion recovery scans of the brain at presentation, showing a high signal in the left PICA. (B) Magnetic resonance angiography scan of the brain at presentation, showing normal findings.

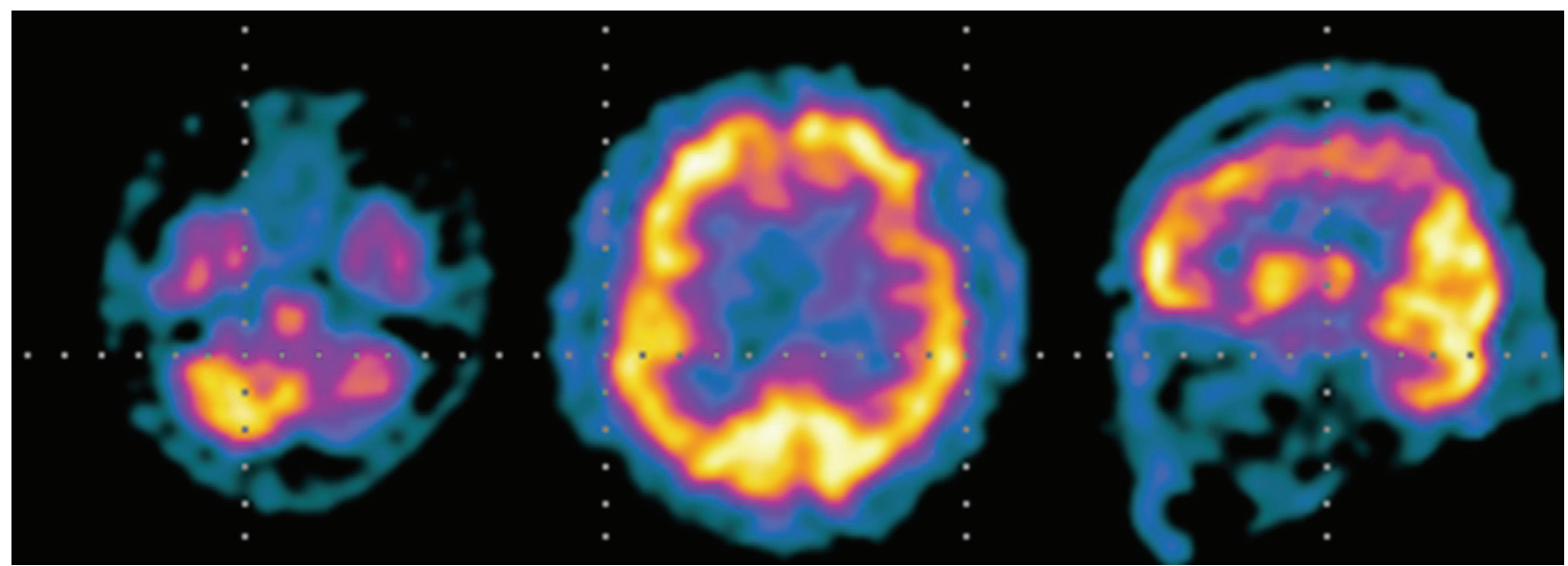

Figure 2. Brain single-photon-emission computed tomography at presentation, showing hypoperfusion in the left cerebellar and frontal cortex.

who presented to an emergency room with an acute onset of AM. His family described him as a calm, intelligent, and cultured individual without any evident cognitive abnormality before the sudden onset of AM.

On examination he was alert but produced no spontaneous speech and exhibited only infrequent spontaneous movements of his arms and legs. With repeated prompting, he followed single-step commands. Magnetic resonance imaging (including diffusionweighted sequences) performed 1 day after the onset of symptoms demonstrated an infarction in the dis- tribution of the left PICA (Fig. 1). Magnetic resonance angiography produced normal findings. The patient became more interactive over the following 7 days, eventually demonstrating normal language function. However, his improved communication revealed the presence of cognitive impairment. A neuropsychological evaluation was performed approximately 12 days after the onset since the test could not be administered during the acute phase.

Table 1 summarizes the patient's performances on neuropsychological tests, corrected for age and edu- 
cation, and compared with published Korean norms. Impaired performances were evident in executive function testing, with difficulties in planning, abstract reasoning, set-shifting, and perseveration. Furthermore, mild attentional disorders and memory dysfunction were observed, which were probably attributable to his poor planning and organization abilities. Language tests revealed mild deficits in the semantic sphere, with paraphasia, anomia, and circumlocutory expressions. During psychometric testing the patient appeared agitated and anxious, with affective air hunger and episodes of crying. Brain single-photon-emission computed tomography (SPECT) performed approximately 14 days after onset demonstrated hypoperfusion in the left cerebellar and frontal cortex (Fig. 2).

Table 1. Results of neuropsychological test

\begin{tabular}{|c|c|}
\hline \multicolumn{2}{|l|}{ Attention } \\
\hline \multicolumn{2}{|l|}{ Digit span } \\
\hline Forward/backward & 4 (22.36\%ile)/ 3 (26.43\%ile) \\
\hline Letter cancellation & Normal \\
\hline \multicolumn{2}{|l|}{ Language } \\
\hline Naming (K-BNT) & 42/60 (57.93\%ile) \\
\hline Other subdomains Normal & \\
\hline \multicolumn{2}{|l|}{ Visuospatial function } \\
\hline Interlocking pentagon & Normal \\
\hline RCFT copy & $25.5 / 36(8.38 \%$ ile $)$ \\
\hline \multicolumn{2}{|l|}{ Memory } \\
\hline Three-word registration/recall & $3 / 0$ \\
\hline \multicolumn{2}{|l|}{ Hopkins verbal learning test } \\
\hline Free recall $\left(1^{\text {st }} / 2^{\text {nd }} / 3^{\text {rd }}\right.$ trials $)$ & 3/4/6 (18.94\%ile) \\
\hline 20-minute delayed recall & 2 (6.06\%ile) \\
\hline Recognition score & 17 (11.31\%ile) \\
\hline \multicolumn{2}{|l|}{ RCFT } \\
\hline Immediate recall & $25.5 / 36(8.38 \%$ ile $)$ \\
\hline 20-minute delayed recall & $5 / 36(8.23 \%$ ile $)$ \\
\hline Recognition score & $4 / 36(6.43 \%$ ile $)$ \\
\hline \multicolumn{2}{|l|}{ Frontal/Executive function } \\
\hline \multicolumn{2}{|l|}{ Word fluency } \\
\hline Animal/supermarket items & 8 (8.38\%ile)/ 7 (8.69\%ile) \\
\hline Phonemic items & $1 / 1 / 5(6.94 \%$ ile $)$ \\
\hline \multicolumn{2}{|l|}{ Stroop test } \\
\hline Letter reading/color reading & 111 ( 1 error $) / 37$ (6 errors) \\
\hline Fist-edge-palm & Impaired \\
\hline Other subdomains & Normal \\
\hline K-MMSE & 23 \\
\hline CDR & 0.5 \\
\hline
\end{tabular}

\section{DISCUSSION}

To our knowledge, this case is the first in vivo description of acute AM produced by a unilateral infarction of the PICA. The syndrome of AM typically results from bilateral hemispheric injury, and usually involves the anterior cingulate gyri. ${ }^{4}$ Other locations for lesions producing AM include the thalami, globus pallidus, internal capsule, and frontal white matter. ${ }^{5}$

These lesions are thought to disrupt anterior frontal subcortical circuits that subserve motivation. ${ }^{8}$ In our patient, AM appeared to have resulted from a cerebellar lesion effectively disconnecting the functional ipsilateral frontal lobe. In effect, this unilateral lesion disrupted bilateral pathways that are necessary for sustaining normal motivation. The involvement of bilateral callosal fibers in the regions of the frontal hyporfunction is another possible explanation.

The cerebellum has long been regarded as contributing to the planning, execution, and modulation of movement. Many studies performed over the past few decades have described the role of the cerebellum in higher order cognitive functions. Recent neuroimaging studies and neuropsychological investigations confirm cerebellar involvement in the modulation of cognitive function. ${ }^{9-12}$ The clinical onset and course, neuroimaging findings, and psychophysiological data led us to the diagnosis of "cerebellar cognitive affective syndrome". Although a single case cannot clarify the causeand-effect relationship between a cerebellar lesion and cognitive impairment, several aspects of the present case are worth noting. First, the executive dysfunctions of our patient probably resulted from alterations to the circuitry of the cerebellar and frontal cortex. Leiner et al. ${ }^{13}$ hypothesized the presence of cerebrocerebellar loops involved in cognitive functions, namely the neocorticopontocerebellar and dentate-thalamoneocortical pathways with prefrontal region 
projections, as subsequently confirmed in monkeys by transneuronal viral transport. ${ }^{14}$ Second, there are cerebellar inputs and outputs to reticular, autonomic, and limbic structures, as well as to associative and paralimbic cerebral regions, ${ }^{15,16}$ which might partly explain the behavioral disorder of our patient. Third, the presence of cerebral inter- and intrahemispheric connections together with the cerebrocerebellar loops probably allow the cerebellar coordination and modulation of higher level cognition. ${ }^{17}$ Lesions or degenerations in these pathways or only in the cerebellum could generate various pathological conditions involving cognitive domains. The association of motor and cognitive features is compatible with the theory of functional cerebellar topography, which postulates an anterior-sensorimotor vs. posterior-cognitive dichotomy. This dichotomy could explain the absence of motor features in our case of cerebellar cognitive affective syndrome secondary to posterior cerebellum damage. Cerebellar mutism is a term that describes anarthria resulting in severe impairment of fluency, articulation, and modulation of speech. ${ }^{18}$ It is mostly transient, occurring after surgery for posterior fossa tumors in children. ${ }^{19}$ The exact mechanisms underlying cerebellar mutism are unknown. Lesions of the dentate nuclei, the dentothalamic tracts, the brachium pontis, and both hydrocephalus and splitting of the inferior vermis have all been reported to cause this condition. A prospective ${ }^{99 \mathrm{~m}} \mathrm{Tc}-\mathrm{HMPAO}$ SPECT study ${ }^{18,19}$ on patients undergoing posterior fossa surgery did not reveal any differences between patients with and without mutism, which suggests that cerebellocerebral diaschisis does not underlie the syndrome. Nonsurgical cerebellar mutism can be caused by trauma, infection, and large or small cerebellar vascular insults. ${ }^{20}$ Here we have reported a case of acute AM and cerebellar cognitive affective syndrome produced by a unilateral infarction of the PICA.

\section{REFERENCES}

1. Ackerman H, Ziegler W. Akinetic mutism - a review of the literature. Fortschr Neurol Psychiatr 1995;63:59-67.
2. Celesia GG. Persistent vegetative state: clinical and ethical issues. Theor Med 1997;18:221-236.

3. American Congress of Rehabilitation Medicine. Recommendations for use of uniform nomenclature pertinent to patients with severe alterations in consciousness. Arch Phys Med Rehabil 1995;76:205-209.

4. Cairns H, Oldfield RC, Pennybacker JB, Whitteridge D. Akinetic mutism with an epidermoid cyst of the 3rd ventricle. Brain 1941;64:273-290.

5. Yamanaka K, Fukuyama H, Kimura J. Abulia from unilateral capsular genu infarction: report of two cases. $J$ Neurol Sci 1996;143:181-184.

6. Riva C, Giorgi C. The cerebellum contributes to higher functions during development: evidence from a series of children surgically treated for posterior fossa tumours. Brain 2000;123:1051-1061.

7. Schmahmann JD, Sherman JC. The cerebellar cognitive affective syndrome. Brain 1998;121:561-579.

8. Mega MS, Cohenour RC. Akinetic mutism: disconnection of frontal-subcortical circuits. Neuropsychiatry Neuropsychol Behav Neurol 1997;10:254-259.

9. Grasby PM, Frith CD, Friston KJ, Bench C, Frackowiak RSJ, Dolan RJ. Functional mapping of brain areas implicated in auditory-verbal memory function. Brain 1993;116:1-20.

10. Fiez JA, Petersen SE, Cheney MK, Raichle ME. Impaired non-motor learning and error detection associated with cerebellar damage. A single case study. Brain 115:1992; 155-178.

11. Drepper J, Timmann D, Kolb FP, Diener HC. Nonmotor associative learning in patients with isolated degenerative cerebellar disease. Brain 1999;122:87-97.

12. Appollonio IM, Grafman J, Schwartz V, Massaquoi S, Hallett M. Memory in patients with cerebellar degeneration. Neurology 1993;43:1536-1544.

13. Leiner HC, Leiner AL, Dow RS. Cerebro-cerebellar learning loops in apes and humans. Ital J Neurol Sci 1987;8:425-436.

14. Middleton FA, Strick PL. Anatomical evidence for cerebellar and basal ganglia involvement in higher cognitive function. Science 1994;266:458-461.

15. Schmahmann JD, Pandya DN. The cerebrocerebellar system. Int Rev Neurobiol 1997;41:31-60.

16. Vokaer M, Bier JC, Elincx S, Claes T, Paquier $\mathrm{P}$, Goldman S, et al. The cerebellum may be directly involved in cognitive functions. Neurology 2002;58:967-970.

17. Ivry RB, Fiez JA. Cerebellar contributions to cognition and imagery. In: Gazzaniga MS (ed) The new cognitive neuroscience. MIT Press, London 2000 pp. 999-1011.

18. Mewasingh LD, Khadim H, Christophe C, Christiaens FJ, Dan B. Nonsurgical cerebellar mutism (anarthria) in two children. Pediatr Neurol 2003;28:59-63. 
19. Rekate HL, Grubb RL, Aram DM, Hahn JF, Ratcheson RA. Muteness of cerebellar origin. Arch Neurol 1985;42: 697-698.
20. Al-Anazi A, Hassounah M, Sheikh B, Barayan S. Cerebellar mutism caused by arteriovenous malformation of the vermis. Br J Neurosurg 2001;15:47-50. 